\title{
Effect of the zinc chelator N,N,N',N'-tetrakis (2-pyridylmethyl)ethylenediamine (TPEN) on hippocampal mossy fiber calcium signals and on synaptic transmission
}

\author{
CARLOS M MATIAS,,$^{1,4}$ NUNO C MATOS, 2 MONA ARIF, ${ }^{2}$ JOSE C DIONISIO ${ }^{3}$ \\ and M EMILIA QUINTA-FERREIRA ${ }^{4,5}$
}

\footnotetext{
${ }^{1}$ Department of Physics, University of Trás-os-Montes and Alto Douro (UTAD), Vila Real, Portugal.

${ }^{2}$ Department of Chemistry, UBI, Covilha, Portugal.

${ }^{3}$ Department of Animal Biology, University of Lisbon, Lisbon, Portugal.

${ }^{4}$ Department of Physics, University of Coimbra, Coimbra, Portugal.

${ }^{5}$ Center for Neuroscience and Cell Biology, University of Coimbra, Coimbra, Portugal.
}

\begin{abstract}
An important pool of chelatable zinc is present in the synaptic vesicles of mossy fiber terminals from hippocampal CA3 area, being zinc released following single or repetitive electrical stimulation. Previous studies have suggested different synaptic roles for released mossy fiber zinc, including the inhibition of presynaptic calcium and of postsynaptic N-methyl-D-aspartate (NMDA) and gamma amino-butiric acid $\left(\mathrm{GABA}_{\mathrm{A}}\right)$ receptors. The effect of endogenously released zinc on mossy fiber long-term potentiation (LTP) induction also is not yet established.

We have investigated the effect of the permeant zinc chelator N,N,N',N'-tetrakis(2-pyridylmethyl) ethylenediamine (TPEN) on mossy fiber calcium and on synaptic transmission, before and during the application of LTP-inducing stimulation. We have found, using the calcium indicator Fura-2, that single and tetanically-evoked mossy fiber calcium signals are both enhanced in the presence of $20 \mu \mathrm{M}$ TPEN, while the single field potentials are unaffected. As expected, no effect was observed on the single calcium signals or field potentials obtained at the CA3-CA1 synapses, from the CA1 area, which has a lower concentration of vesicular zinc. These results support the idea that at the hippocampal mossy fiber synapses, released zinc inhibits presynaptic calcium mechanisms. A higher concentration of TPEN (100 $\mu \mathrm{M})$ significantly reduced mossy fiber synaptic transmission but did not prevent the induction of mossy fiber LTP, suggesting that zinc is not required for the formation of this form of LTP.
\end{abstract}

Key terms: mossy fiber synapses, long-term potentiation (LTP), Area CA3, presynaptic calcium, Fura-2, Area CA1.

PROLOGUE

It was a great privilege for me (ME Q-F) to have had Professor Eduardo Rojas as supervisor during my Ph.D. work carried out at the University of East Anglia, in England, in the period 1978-1981. The first impression I had of him was of a very lively and passionate scientist and scholar, with an extraordinary capacity for work and dedication to science. Among his many gifts, he easily transmitted his enormous enthusiasm for the issues in question, being extremely careful in the experimentation and highly rigorous in the analysis and interpretation of the results. He joyfully shared his vast and thoughtful knowledge with a profound empathy and belief, being highly supportive of all those near him. On the personal level, Eduardo was an extremely friendly, informal and compassionate person, with a special love for music and nature. There were many happy social occasions in which he 
participated or that he and his wife, Illani, organized. I especially remember the parties at their home, where all his Ph.D. students and collaborators were welcome. Besides the special food, there was always a very warm and cultural atmosphere including music and the exchange of ideas about subjects such as literature or social policies.

Thus, the years of my Ph.D. work became a very special period of my life, since due to the unique scientific and human qualities of Eduardo, I could not only get an excellent scientific formation in a friendly and joyful atmosphere, but also profit from his outstanding general knowledge and boundless enthusiasm for life.

\section{INTRODUCTION}

The central nervous system contains high levels of chelatable zinc sequestered in the vesicles of glutamatergic terminals, which are particularly numerous in hippocampal mossy fiber synapses (Frederickson and Danscher, 1990; Frederickson et al., 2000). Zinc is released in a calcium-dependent way, following intense (Assaf and Chung, 1984; Howell et al., 1984) and single (QuintaFerreira et al. 2004) mossy fiber stimulation, being taken up by zinc transport processes (Cole et al., 1999) and refilled into synaptic vesicles within less than one minute (Sudhof, 1995; Clemens, 1996). Vesicular zinc, representing readily available and chelatable zinc, is a minor fraction, approximately $8 \%$, of total zinc in the brain (Frederickson, 1989). The larger fraction is more or less tightly bound to proteins, with zinc being found in metallothioneins, enzymes, structural proteins, and transcription factors (Vallee and Falchuk, 1993; Cuajungco and Lees, 1997). There also are many endogenous zinc chelators, such as amino acids, which have cysteine and hystidine affinities for zinc of between $10^{18} \mathrm{M}^{-1}$ and $10^{12} \mathrm{M}^{-1}$, respectively, and proteins with lower affinities, approximately $10^{7} \mathrm{M}^{-1}$ (Cuajungco and Lees, 1997). Thus, the intracellular resting zinc concentration is tightly regulated probably being in the subnanomolar range due to high-affinity binding (Frederickson et al., 2000).
Zinc interacts with several neurotransmitter receptors and ion channels (Harrison and Gibbons, 1994; Smart et al., 1994) and is thought to have a neuromodulatory role at the mossy fiber synapses, which contain a very high density of ATP-sensitive potassium channels (Mourre et al., 1991; Tremblay et al., 1991; Zawar et al., 1999). At those synapses, zinc inhibits postsynaptic NMDA and $\mathrm{GABA}_{\mathrm{A}}$ receptor activity (Vogt et al., 2000; Ruiz et al., 2004, but see also Lopanstev et al., 2003), presynaptic calcium mechanisms, possibly voltage-dependent calcium channels (Xie and Smart, 1994; Quinta-Ferreira and Matias, 2004), and activates presynaptic ATPsensitive potassium channels (Bancila et al., 2004). It also has been reported that zinc may enter neurons through voltage-dependent calcium channels or via AMPA/kainate and NMDA receptor channels (Sensi et al., 1997; Marin et al., 2000) and that intense zinc release may lead to zinc neurotoxicity and neuronal disorders (Cuajungco and Lees, 1997; Choi and Koh, 1998; Weiss et al., 2000; Frederickson et al., 2005). The effects of excessive zinc exposure may be prevented or attenuated by zinc chelators, which in this case have a neuroprotective action. On the other hand, chelators may cause a toxic effect if they remove metal ions from high-affinity binding sites on intracellular proteins, which are required for normal activity. This has been proposed for the permeant heavy metal chelator $\mathrm{N}, \mathrm{N}, \mathrm{N}^{\prime}, \mathrm{N}^{\prime}$-tetrakis(2-pyridylmethyl) ethylenediamine (TPEN), which is considered to be intrinsically toxic at high concentrations (Ahn et al., 1998; Armstrong et al., 2001; Canzoniero et al., 2003).

The mossy fiber synapses have a characteristic form of long-term potentiation (LTP) that is independent of the activation of $\mathrm{N}$-methyl-D-aspartate (NMDA) receptors, and it is generally considered that its expression is mediated by an increase in neurotransmitter release (Nicoll and Malenka, 1995). The role of zinc on mossy fiber synaptic transmission and plasticity processes has been the subject of various studies, namely on the effect of zinc on normal synaptic transmission, paired-pulse facilitation, and mossy fiber LTP. No substantial controversy exists about the first 
two processes. It is generally assumed that endogenously released zinc has no effect on normal synaptic transmission (Xie and Smart, 1994; Vogt et al., 2000; Li et al., 2001a; Lopantsev et al., 2003) or pairedpulse facilitation (Khulusi et al., 1986). However, the role of zinc in the formation of mossy fiber LTP is not yet established, leading different experimental conditions to two types of results. Application of the permeant zinc chelator 1,2 diethyl-3hidroxy-pyridine (CP94) (Xie and Smart, 1994), the extracellular chelator Ca-EDTA (Vogt et al., 2000) or the permeant zinc chelator TPEN (Quinta-Ferreira and Matias, 2004) did not affect the induction of LTP. Consistent with this, mossy fiber LTP also was induced in transgenic mice, lacking the ZnT3 transporter and, thus, chelatable zinc (Vogt et al., 2000). However, in other studies using methods like dietary depletion of zinc ( $\mathrm{Lu}$ et al., 2000), or different chelators, such as dithizone (Lu et al., 2000) or a higher concentration of Ca-EDTA ( $\mathrm{Li}$ et al., 2001a), there was no formation of LTP, suggesting that zinc is implicated in mossy fiber LTP induction.

Despite the considerable amount of information about the processes involved in normal mossy fiber synaptic transmission and LTP, the way that released zinc affects presynaptic calcium during these forms of activity is not well known. We have shown previously that, following the induction of mossy fiber LTP, the zinc chelator TPEN (20 $\mu \mathrm{M})$, which has a very high affinity for zinc and a low affinity for calcium and magnesium (Arslan et al., 1985), enhances single-stimuli evoked calcium signals but not the associated field potentials (Quinta-Ferreira and Matias, 2004). These results and the fact that we have observed post-tetanic depressions in normal medium in single post-LTP calcium signals, with the depressions blocked by TPEN, support the idea that released mossy fiber zinc inhibits presynaptic calcium (Quinta-Ferreira and Matias, 2004; 2005). In the present work, we have investigated whether the aforementioned calcium enhancement also occurs in the absence of LTP and during LTPinducing stimulation. For this purpose, we have measured presynaptic Fura-2 calcium transients, evoked by single or tetanic stimulation, at the zinc-enriched mossy fiber synapses and also, for comparison, at the CA3-CA1 synapses from hippocampal CA1 area. Previous work has reported a concentration-dependent effect of the zinc chelator Ca-EDTA on mossy fiber LTP induction (Li et al., 2001a). Bearing mind that $20 \mu \mathrm{M}$ TPEN did not prevent the formation of mossy fiber LTP (Quinta-Ferreira and Matias, 2004), we also addressed the question as to whether a higher concentration of TPEN might block the induction of this form of LTP, taking into account the possible intrinsic toxicity of this chelator (Ahn et al., 1998; Canzoniero et al., 2003).

Part of the present results have been reported in abstract form (Quinta-Ferreira and Matias, 2002).

\section{EXPERIMENTAL METHODS}

All the studies involving animals were in agreement with the Guiding Principles in the Care and Use of Laboratory Animals from the European Union.

\section{Electrophysiology}

Young adult Wistar rats (4-6 weeks old) were anaesthetized with ethyl-eter and quickly decapitated. Transverse hippocampal slices (400 $\mu \mathrm{m}$ thick) were prepared and maintained in artificial cerebrospinal fluid (ACSF) containing (in $\mathrm{mM}$ ): $\mathrm{NaCl} 124 ; \mathrm{KCl}$ 3.5; $\mathrm{NaHCO}_{3} 24.0 ; \mathrm{NaH}_{2} \mathrm{PO}_{4} 1.25 ; \mathrm{MgCl}_{2}$ $2.0 ; \mathrm{CaCl}_{2} 2.0$ and glucose 10 , at $\mathrm{pH}=7.2$ 7.4. The slices were gassed with $95 \% 0_{2}, 5 \%$ $\mathrm{CO}_{2}$ and after a resting period of one hour, transferred to the recording chamber $(\mathrm{T}=$ $\left.30-32^{\circ} \mathrm{C}\right)$. Mossy fiber/CA3 pyramidal cell synapses or CA3-CA1 synapses were stimulated using a stainless steel bipolar electrode placed at the mossy fiber tract or at the Schaffer collateral fibers, respectively. Extracellular potentials were recorded using glass micropipettes filled with $2 \mathrm{M} \mathrm{NaCl}$ (1$5 \mathrm{M} \Omega$ resistance), placed at the CA3 or CA1 pyramidal layers. Only the slices that exhibited paired-pulse facilitation $(50 \mathrm{~ms}$ interval) were accepted for further studies. The current intensity was set at $40 \%$ of the saturation value $(100-400 \mu \mathrm{A})$, and the slices 
stimulated at the control frequency $(0.016$ $\mathrm{Hz}$ ), except during the tetani. LTP was induced by two trains of 100 stimuli (100 $\mathrm{Hz}, 1 \mathrm{~s}$ ), separated by a $30 \mathrm{~s}$ interval. The evaluated parameter was the amplitude of the population spikes, with the baseline value being the average of the first ten records.

\section{Calcium measurements}

Presynaptic calcium transients were measured more than one hour after local injection of the permeant form of the fluorescent calcium indicator Fura-2. The solution (0.9 mM Fura-2, 10\% Dimethylsulfoxide (DMSO) and 1\% pluronic acid) was pressure injected in the mossy fiber pathway. Fluorescent calcium signals were detected using an optical transfluorescence setup, with a xenon lamp and a single silicon photodiode. Fluorescence excitation and emission wavelengths were selected by means of a narrowband pass filter $(380 \mathrm{~nm}$, $10 \mathrm{~nm}$ bandwidth) and a long bandpass emission filter $(>500 \mathrm{~nm})$, respectively. The signal from the photodiode passed through an I/V converter with a very high feedback resistance $(1 \mathrm{G} \Omega)$, and the output from this unit was introduced into one AC-coupled amplifier with a low cutoff frequency $(1 \mathrm{~Hz})$.

The optical traces show fractional changes $(\Delta \mathrm{F} / \mathrm{F})$, where $\Delta \mathrm{F}$ represents the change in fluorescence induced by electrical stimulation and $\mathrm{F}$, the resting fluorescence corrected for background fluorescence. This value was measured at an equivalent region of the slice containing no dye-related fluorescence.

\section{Drug application}

Because of the complex circuitry of the hippocampal CA3 area, the group II metabotropic glutamate agonist (2S, 2R, 3'R)2-2-(2'3' Dicarboxylcyclopropylglicine (DCG-IV) $(1 \mu \mathrm{M}))$ was used at the end of the experiments performed in the $\mathrm{CA} 3$ area to verify if the signals of interest had mossy fiber origin (Kamiya and Ozawa, 1999). The permeant zinc chelator TPEN $(20 \mu \mathrm{M}$ or 100 $\mu \mathrm{M})$ and the drugs 6-cyano-7nitroquinoxaline-2,3-dione (CNQX) $(10 \mu \mathrm{M})$ and D(-)-2-amino-5-phosphonopentanoic acid (D-APV) $(50 \mu \mathrm{M})$, antagonists of AMPA and NMDA receptors, respectively, were applied in the perfusate. All drugs were applied for periods of 40-90 min. The solutions containing them where recirculated normally, using $100 \mathrm{ml}$ of solution.

Data are expressed as mean \pm S.E.M. Statistical significance was evaluated using the Student's t-test $(\mathrm{p}<0.05)$.

Drugs used were TPEN, Fura-2, Pluronic F127 (Molecular Probes Europe BV, Leiden NL); DMSO (Sigma); CNQX, D-APV, DCG-IV (Tocris Cookson, Bristol, UK).

\section{RESULTS}

\section{Effect of TPEN on single and tetanic calcium transients and field potentials}

We have shown previously that after LTP formation, the heavy metal chelator TPEN (at a concentration of $20 \mu \mathrm{M}$ ) leads to an enhancement of single-stimuli-evoked calcium transients, with no significant effect on synaptic transmission (QuintaFerreira and Matias, 2004). The effect of the same concentration of TPEN was now observed in LTP-naïve slices. The left panels of Figure 1 show the effect of TPEN $(20 \mu \mathrm{M})$ on single presynaptic calcium signals (upper panel) and on the corresponding field potentials (lower panel), induced by mossy fiber activation. In each panel, the upper traces show sample signals, representing the optical calcium transients relative fluorescence changes $(\Delta \mathrm{F} / \mathrm{F})$ of about $1 \%$. The graphs represent the average normalized amplitude of the signals from various experiments. In each experiment, the amplitudes were normalized by the average amplitude of the values recorded in the control solution (ACSF). In these experiments, the application of TPEN caused an increase in the normalized amplitude of the calcium transients, of $19 \pm 3 \%$ (mean \pm S.E.M.; $n=$ 2) with respect to control, at 60-70 minutes after the addition of the chelator, as can be observed in the graph (Fig. 1a). As expected, those signals were not affected significantly by the antagonists of the 

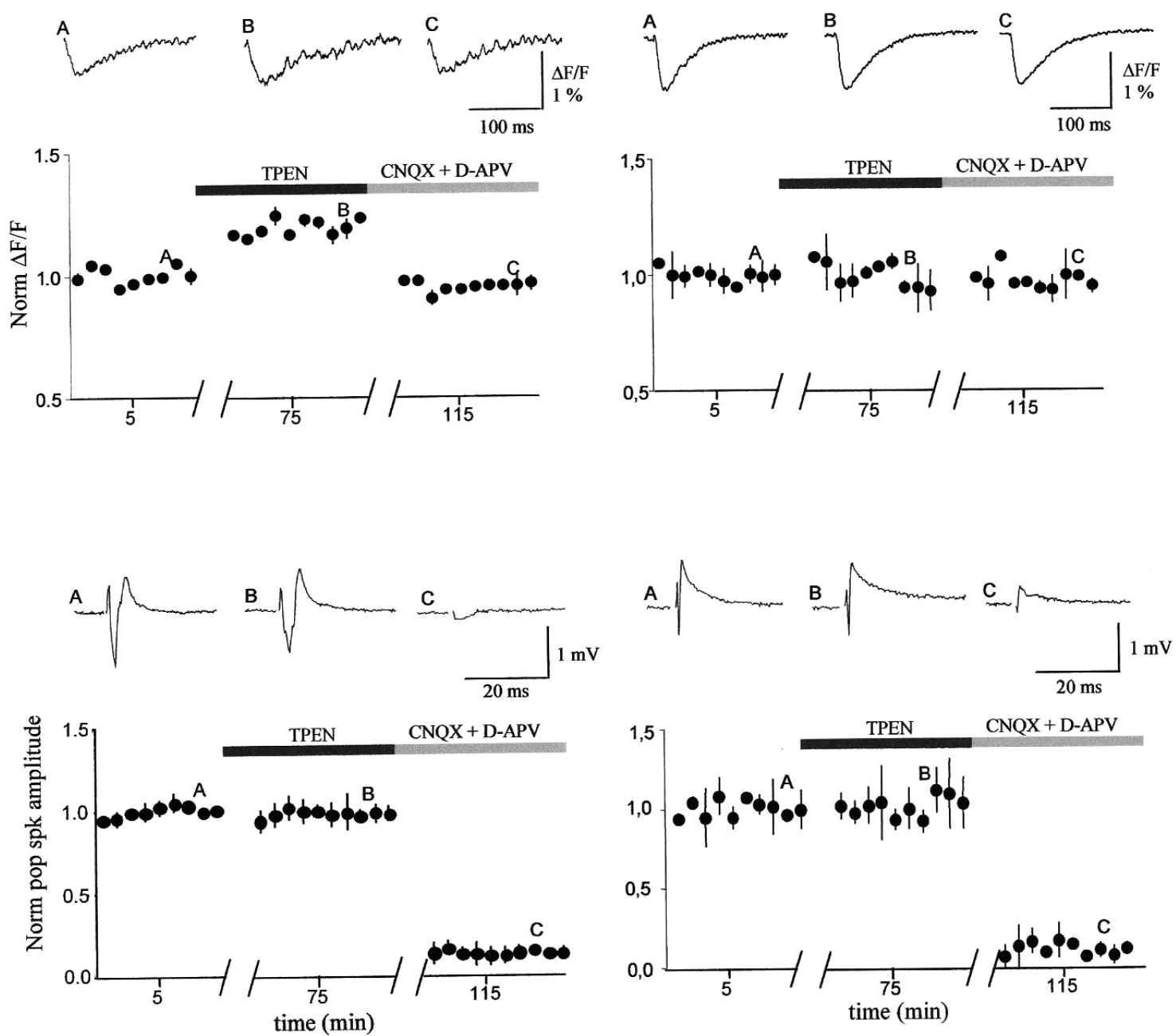

Figure 1. The zinc chelator TPEN enhances calcium transients evoked by mossy fiber but not by Schaffer-collaterals stimulation. A. Fura-2/calcium sample transients (upper part) and normalized amplitude of the calcium signals (lower part) in the presence of ACSF, TPEN (20 $\mu \mathrm{M})$ (dark bar) and CNQX $(10 \mu \mathrm{M})$ plus D-APV $(50 \mu \mathrm{M})$ (light bar) $(\mathrm{n}=2)$. B. Sample field potentials (upper part) and normalized amplitude of the population spikes (lower part) in the presence of ACSF (first 9 points, forming the baseline) and in TPEN $(20 \mu \mathrm{M})$ (dark bar) and CNQX $(10 \mu \mathrm{M})$ plus D-APV $(50 \mu \mathrm{M})$ (light bar) solutions $(\mathrm{n}=3)$. C. Same as A, for calcium signals evoked by stimulation of the Schaffercollateral fibers and recorded in the CA1 area $(n=3)$. D. Same as B, for field potentials induced by stimulation of the Schaffer-collaterals and recorded in the CA1 somatic area $(n=3)$. The sample traces A-C were measured at the times indicated by the letters in the graphs and are the average of 10 (a) or 5 (b-d) consecutive records. The interruptions in the time axis correspond to the initial period ( $1 \mathrm{~h}$ for TPEN and $1 / 2 \mathrm{~h}$ for CNQX+D-APV) of the change of solutions, with the slices being stimulated at the control frequency $(0.016 \mathrm{~Hz})$ throughout all the experiment. Data are reported as mean \pm S.E.M. All stimuli were given at baseline stimulus strength.

AMPA and NMDA glutamate receptors, CNQX $(10 \mu \mathrm{M})$ and D-APV $(50 \mu \mathrm{M})$, respectively, which confirms their presynaptic nature. Figure $1 \mathrm{~b}$ shows the effect of TPEN on corresponding field potentials, evoked by single stimuli. No significant differences were observed between the amplitudes of the population spikes in the control and in the TPEN solutions, with the latter measuring $98 \pm 6$ 
$\%$ (mean \pm S.E.M.; $\mathrm{n}=3$ ) of the control values. The right panels (Figs. 1c and d) show the effect of TPEN $(20 \mu \mathrm{M})$ on calcium transients and field potentials evoked by stimulation of the Schaffer collateral-commissural pathway and recorded at the CA3-CA1 pyramidal cell synapses in CA1 hippocampal area $(n=3)$. Both types of signals are maintained in the presence of TPEN suggesting that, in this synaptic system, released zinc, evoked by single stimuli, does not alter presynaptic calcium or normal transmission.

We also have investigated the effect of TPEN $(20 \mu \mathrm{M})$ on calcium signals induced by tetanic stimulation $(100 \mathrm{~Hz}, 1 \mathrm{~s})$, normally used to elicit LTP. In these experiments, the application of TPEN leads to an increase of the tetanically-evoked calcium transients, of $18 \pm 5 \%$ (mean \pm S.E.M.; $\mathrm{n}=5$ ) with respect to the control signals, obtained in normal medium (Fig. 2) These results suggest that the action of TPEN $(20 \mu \mathrm{M})$ is similar for both the single and tetanic calcium responses and that this concentration of TPEN does not affect normal synaptic transmission.

Effect of a higher concentration of TPEN on synaptic transmission and LTP induction

At the concentration previously used (20 $\mu \mathrm{M})$, TPEN enhanced presynaptic calcium but had no effect on either synaptic transmission or LTP induction. In order to verify if TPEN acted in a concentrationdependent manner in the latter processes, we applied a higher concentration of TPEN $(100 \mu \mathrm{M})$ in experiments designed to tetanically evoke LTP. In that medium, the field potentials evoked by mossy fiber activation were markedly reduced, to $62 \pm 2$ $\%$ (mean \pm S.E.M.; $\mathrm{n}=3$ ) of their initial amplitude, with the application of TPEN $(100 \mu \mathrm{M})$ (Fig. 3). However, even under these conditions, TPEN did not block LTP induction triggered by the delivery of two tetani $(100 \mathrm{~Hz}, 1 \mathrm{~s})$. As can be observed in Fig. 3, the amplitude of the elicited LTP, represented by the amplitude of the population spikes recorded 20-30 min after tetanic stimulation, was $52 \pm 7 \%$ (mean \pm S.E.M.; $\mathrm{n}=3$ ) higher than that of the ten pre-tetani values. The amplitude of the population spikes was also strongly reduced, to $32 \pm 7 \%$ of that of the initial (ACSF) values, by the application of DCGIV $(1 \mu \mathrm{M})$. This fact is in agreement with previous findings (Kamiya and Ozawa, 1999) and rules out the existence of significant contamination by associational/ commissural fiber activation. These results suggest that at higher doses, up to a concentration of $100 \mu \mathrm{M}$, TPEN partially blocks synaptic transmission, but does not prevent LTP formation.

\section{Control}
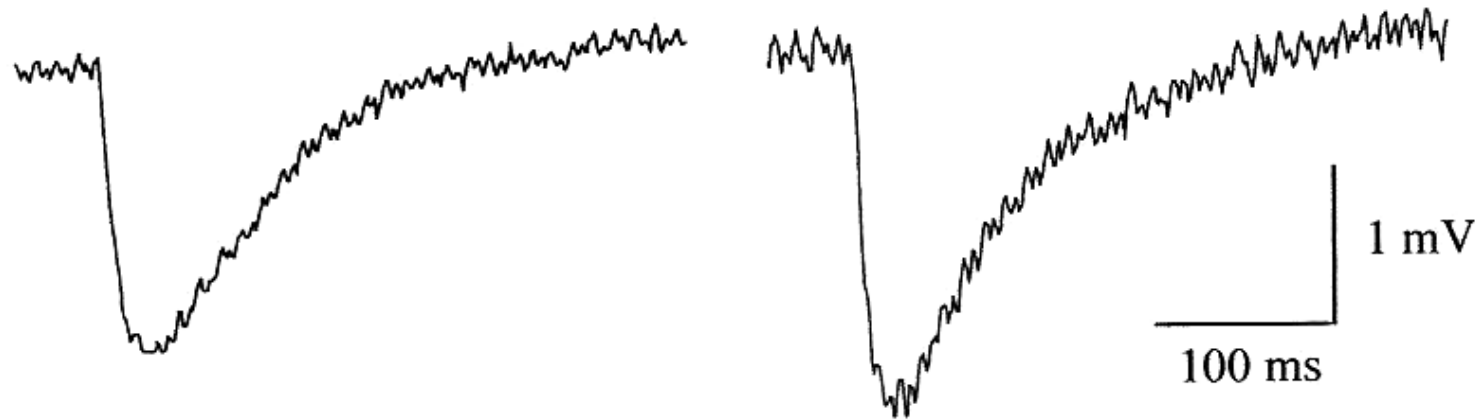

Figure 2. TPEN enhances tetanically evoked mossy fiber calcium transients. Presynaptic Fura-2/ calcium signals evoked by one tetanus $(100 \mathrm{~Hz}, 1 \mathrm{~s})$ applied at the mossy fiber pathway, in ACSF and in the presence of TPEN $(20 \mu \mathrm{M})$. 


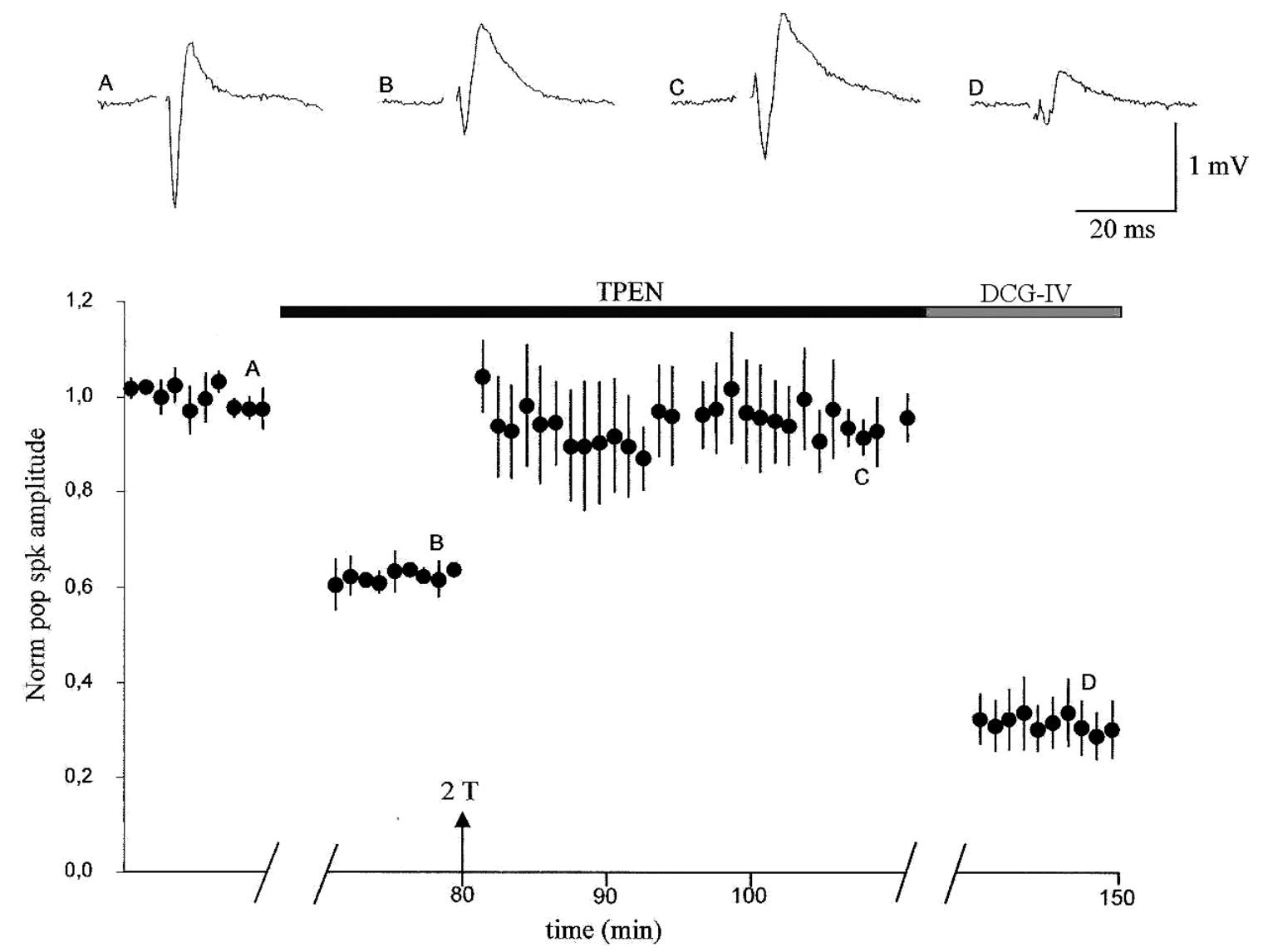

Figure 3. The application of TPEN partially blocked synaptic transmission but did not prevent the induction of mossy fiber LTP. Sample field potentials (upper part) and normalized amplitude of population spikes (lower part) in ACSF and in the presence of TPEN (100 $\mu \mathrm{M}$, dark bar) and DCGIV $(1 \mu \mathrm{M}$, light bar) $(\mathrm{n}=3)$. The arrow indicates the time of application of two tetani $(100 \mathrm{~Hz}, 1 \mathrm{~s}$, each), given to induce LTP. The sample traces A-D were measured at the times indicated by the capital letters in the graphs and are the average of 5 consecutive records. No data was recorded during the initial period of application of the drugs ( $1 \mathrm{~h}$ for TPEN and $1 / 2 \mathrm{~h}$ for DCG-IV), represented by the parallel traces in the time axis, with the slices being stimulated at the control frequency $(0.016 \mathrm{~Hz})$ throughout the experiment. Data are reported as mean \pm S.E.M. All stimuli were delivered at baseline stimulus strength.

\section{DISCUSSION}

The first part of this study shows that single-stimuli evoked mossy fiber calcium signals, obtained in the presence of the permeant zinc chelator TPEN $(20 \mu \mathrm{M})$, are enhanced with respect to control values. The corresponding field potentials, recorded in the same medium, are not altered in agreement with the results of previous zinc- chelating and knockout studies, showing that normal zinc release has no effect on synaptic strength (Xie and Smart, 1994; Vogt et al., 2000; Li et al., 2001; Lopantsev et al., 2003). Thus, the present data show a differential effect of TPEN on the calcium responses and field potentials, which is similar to that described for the same signals during mossy fiber LTP (Quinta-Ferreira and Matias, 2004). As proposed for the CA3-CA1 synapses in CA1 area (Wu and Saggau, 1997), this type of effect might be due to the existence of a nonlinear relationship between postsynaptic 
potential and presynaptic calcium concentration. In the present work, TPEN $(20 \mu \mathrm{M})$ also caused an enhancement on presynaptic calcium changes evoked by one tetanus. These results suggest that in normal medium both single and tetanically evoked mossy fiber calcium responses are inhibited by released zinc, with the singlefield potentials remaining unaltered. However, following an abundant zinc release caused by multiple tetanic stimulation, an inhibitory effect that was blocked by TPEN $(20 \mu \mathrm{M})$ was observed in both single calcium transients and field potentials (Quinta-Ferreira and Matias; 2005). This suggests that intense zinc release depresses both presynaptic calcium and excitatory transmission, the depression of the field potentials being consistent with the reported inhibitory action of high levels of exogenous zinc on synaptic transmission (Xie and Smart, 1994). Reduced calcium influx, following both single and tetanic stimulation, could occur via the inhibition of presynaptic voltage-dependent calcium channels, through direct (Harrison and Gibbons, 1994) or indirect zinc actions. In the latter case, the inhibition of those channels might be caused by cell hyperpolarization following activation by zinc of presynaptic ATP-sensitive potassium channels (Bancila et al., 2004). As expected, at the CA3-CA1 synapses, characterized by a lower concentration of vesicular zinc (Frederickson and Danscher, 1990), the same concentration of TPEN (20 $\mu \mathrm{M})$ had no effect on either the single calcium signals or the single-field potentials. Thus, the observations support the idea that the calcium enhancement, caused by TPEN, is specific for the zincrich mossy fiber synapses.

It should be noted that the calcium signals were obtained with the permeant form of Fura-2, which has a much higher affinity for zinc than for calcium (Grynkiewicz et al., 1985). Thus, in order to detect presynaptic calcium changes independent of Fura-2/zinc complexation, the optical traces were recorded using an excitation wavelength of $380 \mathrm{~nm}$, close to the isosbestic point of the Fura-2/zinc complex (Grynkiewicz et al., 1985; Vega et al., 1994). Also, it could be argued that the observed calcium enhancements reflect a TPEN-evoked change in the properties of the free or calcium-complexed Fura-2 spectra, instead of a zinc effect on presynaptic calcium. This possibility was ruled out based on cuvette fluorescence studies that have shown that TPEN has no effect on those Fura-2 types of spectra (unpublished observations).

In relation to the effect of zinc on LTP induction, it has been reported that the impermeant zinc-chelating agent Ca-EDTA acts in a dose-dependent manner: low concentrations of Ca-EDTA (1-2.5 mM) did not affect mossy fiber LTP induction (Vogt et al., 2000; Li et al., 2001a), while higher concentrations $(10 \mathrm{mM})$ prevented its formation (Li et al., 2001a). We have observed a lack of effect of TPEN on mossy fiber LTP induction in the presence of both low $(20 \mu \mathrm{M})$ and high $(100 \mu \mathrm{M})$ concentrations of this chelator, in spite of the fact that the higher concentration depressed the field potentials and, thus, synaptic transmission.

The depressant action of the higher concentration of TPEN $(100 \mu \mathrm{M})$ on synaptic transmission, which also was observed during LTP (data not shown), could be due to its intrinsic toxicity, as a consequence of non-physiological lowering of intracellular tightly bound zinc (Cuajungco and Lees, 1997; Ahn et al., 1998; Canzoniero et al., 2003). The extremely large affinity of TPEN for zinc $\left(10^{15} \mathrm{M}^{-1}\right)$ (Arslan et al, 1985), which is higher than that of zinc for metallothioneins $\left(10^{13} \mathrm{M}^{-1}\right)$ and proteins $\left(10^{7} \mathrm{M}^{-1}\right)$, could lead to the complexation and, consequently, reduced availability of these components of endogenous zinc, which are required for normal cellular functions (Ahn et al., 1998; Canzoniero et al., 2003).

In the present work, we have observed the formation of LTP in the presence of the permeant zinc chelator TPEN during both normal transmission and TPEN-evoked decreased activity. Our results are thus in agreement with the idea that the induction of mossy fiber LTP is not mediated by released zinc. This idea is supported by data of other zinc-complexation studies (Xie and Smart, 
1994; Vogt et al., 2000) and by the findings that in transgenic mice, which are unable to stain zinc in the mossy fiber pathway, tetanic stimulation-induced mossy fiber LTP as in normal animals (Vogt et al., 2000). On the other hand, the observations that mossy fiber LTP was impaired following a low-zinc diet (Lu et al., 2000) or in the presence of a large concentration of an impermeant zinc chelator (Li et al., 2001a), suggest that zinc is involved in the formation of LTP. In line with this observation. it has been proposed that released zinc enters the postsynaptic terminal where it acts as a second messenger in LTP formation (Li et al., 2001a, b).

The reason for the different results is not known but may be related to the fact that the various experimental approaches may lead to different intracellular zinc availability and metal/chelator complexes. These could be formed with other physiological heavy metals, besides zinc, particularly iron and copper, some of which are potentially toxic (Armstrong et al., 2001). In addition, depending on the amount of both zinc released and chelator present, exogenous chelators might have either a neuroprotective or neurotoxic effect, based on their ability to lower pathological or normal endogenous zinc levels, respectively (Cuajungco and Lees, 1998; Armstrong et al., 2001). The difference between the environments of action, intra- or extracellular, for membrane-permeant and impermeant chelators, respectively, containing different zinc-binding ligands (Frederickson et al., 2000), also may contribute to the observed differences. For example, it has been shown that zinc-deficient diets lead to $30 \%$ reduction in mossy fiber zinc (Wensink et al., 1987). Furthermore, it has been reported that, in in vivo studies, TPEN can prevent zinc and iron neurotoxicities but not copper toxicity, in spite of the fact that it has a much higher affinity for copper $\left(10^{20} \mathrm{M}^{-1}\right)$ than for zinc $\left(10^{15} \mathrm{M}^{-1}\right)$ (Armstrong et al., 2001). However, in the same work, CaEDTA could prevent the toxicity of the three metal ions.

Thus, the existence of two types of results concerning the requirement of zinc for mossy fiber LTP induction suggests that more work needs to be done before this issue is resolved. Also, the involvement and relative contribution of presynaptic calcium mechanisms, in particular voltagedependent calcium channels and ATPsensitive potassium channels, in calciummediated inhibitory zinc effects requires further studies. More generally, the conditions under which different zincsensitive mechanisms mediate the zinc actions observed both in physiological and in pathological states remains to be clarified.

\section{ACKNOWLEDGMENTS}

We thank the Laboratory of Experimental Research of the Hospital of the University of Coimbra, Portugal, and the Institute of Pharmacology and Experimental Therapeutics of the School of Medicine of the University of Coimbra, Portugal, for collaboration in parts of the work. We are grateful to Dr. P. Saggau for invaluable assistance and advice in setting up the optical system. We also thank Dr. F.H. Lopes da Silva for his comments. This work was supported by Pluriannual of CNC.

\section{REFERENCES}

AHN YH, KIM YH, HONG SH, KOH JY (1998) Depletion of intracellular zinc induces protein synthesisdependent neuronal apoptosis in mouse cortical culture. Exp Neurol 154: 47-56

ARSLAN P, DI VIRGILIO F, BELTRAME M, TSIEN RY, POZZAN T (1985) Cytosolic Ca2+ homeostasis in Ehrlich and Yoshida carcinomas. A new, membranepermeant chelator of heavy metals reveals that these ascites tumor cell lines have normal cytosolic free Ca2+. J Biol Chem 260: 2719-2727

ARMSTRONG C, LEONG W, LEES GJ (2001) Comparative effects of metal chelating agents on the neuronal cytotoxicity induced by copper $(\mathrm{Cu}+2)$, iron $(\mathrm{Fe}+3)$ and zinc in the hippocampus. Brain Res 892: 51-62

ASSAF SY, CHUNG SH (1984) Release of endogenous $\mathrm{Zn} 2+$ from brain tissue during activity. Nature 308 : 734-736

BANCILA V, NIKONENKO N, DUNANT Y, BLOC A (2004) Zinc inhibits glutamate release via activation of pre-synaptic $\mathrm{K}$ channels and reduces ischaemic damage in rat hippocampus J Neurochem 90: 1243-50

CANZONIERO LM, MANZERRA P, SHELINE CT, CHOI DW (2003) Membrane-permeant chelators can attenuate $\mathrm{Zn} 2+-$ induced cortical neuronal death. Neuropharmacology 45: 420-428 
CHOI DW, KOH JY (1998) Zinc and brain injury. Annu Rev Neurosci 21: 347-375

CLEMENS JD (1996) Transmitter timecourse in the synaptic cleft: its role in central synaptic function. TINS 19: 163-171

COLE TB, WENZEL HJ, KAFER KE, SCHWARTZKROIN PA, PALMITER RD (1999) Elimination of zinc from synaptic vesicles in the intact mouse brain by disruption of the ZnT3 gene. Proc Natl Acad Sci USA 96: 1716-1721

CUAJUNGCO MP, LEES GJ (1997) Zinc metabolism in the brain: relevance to human neurodegenerative disorders. Neurobiol Dis 4: 137-169

CUAJUNGCO MP, LEES GJ (1998) Diverse effects of metal chelating agents on the neuronal cytotoxicity of zinc in the hippocampus. Brain Res 799: 97-107

FREDERICKSON CJ (1989) Neurobiology of zinc and zinc-containing neurons. Int. Rev. Neurobiol. 31: 145238

FREDERICKSON CJ, DANSCHER G (1990) Zinccontaining neurons in hippocampus and related CNS structures. Prog Brain Res 83: 71-84

FREDERICKSON CJ, SUH SW, SILVA D, FREDERICKSON CJ, THOMPSON RB (2000) Importance of zinc in the central nervous system: the zinc-containing neuron. J Nutr 130: 1471S-1483S

FREDERICKSON CJ, KOH JY, BUSH AI (2005) The neurobiology of zinc in health and disease. Nat Rev Neurosci 6: 449-462

GRYNKIEWICZ G, POENIE M, TSIEN RY (1985) A new generation of $\mathrm{Ca} 2+$ indicators with greatly improved fluorescence properties. J Biol Chem 260: 3440-3450

HARRISON N, GIBBONS S (1994) $\mathrm{Zn}^{2+}$ : An endogenous modulator of ligand- and voltage-gated ion channels. Neuropharmacology 33: 935-952

HOWELL GA, WELCH MG, FREDERICKSON CJ (1984) Stimulation-induced uptake and release of zinc in hippocampal slices. Nature 308: 736-738

KAMIYA Y, OZAWA S (1999) Dual mechanism for presynaptic modulation by axonal metabotropic glutamate receptor at the mouse mossy fibre-CA3 synapse. J Physiol 518: 497-506

KHULUSI S, BROWN M, WRIGHT M (1986) Zinc and paired-pulse potentiation in the hippocampus. Brain Res 363: 152-155

LI Y, HOUGH CJ, FREDERICKSON CJ, SARVEY JM (2001a) Induction of mossy fiber $\rightarrow$ Ca3 long-term potentiation requires translocation of synaptically released Zn2. J Neurosci 21: 8015-8025

LI Y, HOUGH CJ, SUH SH, FREDERICKSON CJ, SARVEY JM (2001b) Rapid translocation of $\mathrm{Zn}(2+)$ from presynaptic terminals into postsynaptic hippocampal neurons after physiological stimulation. J Neurophysiol 86: 2597-2604

LOPANTSEV V, WENZEL HJ, COLE TB, PALMITER RD, SCHWARTZKROIN PA (2003) Lack of vesicular zinc in mossy fibers does not affect synaptic excitability of CA3 pyramidal cells in zinc transporter 3 knockout mice. Neuroscience 116: 237-248

LU YM, TAVERNA FA, TU R., ACKERLEY CA, WANG YT, RODER J (2000) Endogenous Zn (2+). is required for the induction of long-term potentiation at rat hippocampal mossy fiber-CA3 synapses. Synapse 38: 187-197

MARÍN P, ISRAEL M, GLOWINSKI M, PREMONT J (2000) Routes of zinc entry in mouse cortical neurons: role in zinc-induced neurotoxicity. Eur J Neurosci 12: $8-18$
MOURRE C, WIDMANN C, LAZDUNSKI M (1991) Specific hippocampal lesions indicate the presence of sulfonylurea binding sites associated to ATP-sensitive $\mathrm{K}+$ channels both post-synaptically and on mossy fibers. Brain Res 540: 340-344

NICOLL RA, MALENKA RC (1995) Contrasting properties of two forms of long-term potentiation in the hippocampus. Nature 377: 115-118

QUINTA-FERREIRA ME, MATIAS CM (2002) Zinc inhibits presynaptic calcium influxes in $\mathrm{CA} 3$ but not in CA1 hippocampal area. FENS Abstr 1: A115.12

QUINTA-FERREIRA ME， MATIAS CM (2004) Presynaptic calcium changes are maintained during hippocampal mossy fiber long-term potentiation and are inhibited by endogenous zinc. Brain Res 1004: 5260

QUINTA-FERREIRA ME, MATIAS CM, ARIF M, DIONISIO JC (2004) Measurement of presynaptic zinc changes in hippocampal mossy fibers. Brain Res 1026: $1-10$

QUINTA-FERREIRA ME， MATIAS CM (2005) Tetanically released zinc inhibits hippocampal mossy fiber calcium, zinc and synaptic responses. Brain Res 1047: 1-9

RUIZ A, WALKER M, FABIAN-FINE R, KULLMANN D (2004) Endogenous zinc inhibits GABA(A) receptors in a hippocampal pathway. Neurophysiol 91: 10911096

SENSI SL, CANZONIERO LM, YU SP, YING HS, KOH JY, KERCHNER GA, CHOI DW (1997) Measurement of intracellular free zinc in living cortical neurons: routes of entry. J Neurosci 17(24): 9554-64

SMART TG, XIE X, KRISHEK BJ (1994) Modulation of inhibitory and excitatory amino acid receptor ion channels by zinc. Progr Neurobiol 42: 393-441

SUDHOF TC (1995) The synaptic vesicle cycle: A cascade of protein-protein interactions. Nature 375: 645-653

TREMBLAY E, ZINI S, BEN-ARI Y (1991) Autoradiographic study of the cellular localization of $[3 \mathrm{H}]$ glibenclamide binding sites in the rat hippocampus. Neurosci Lett 127: 21-24

VALLEE BL, FALCHUK KH (1993) The biochemical basis of zinc physiology. Physiol Rev 73: 79-118

VEGA MT, VILLALOBOS C, GARRIDO B, GANDIA L, BULBENA O, GARCÍA-SANCHO J, GARCÍA AG, ARTALEJO AR (1994) Permeation by zinc of bovine chromaffin cell calcium channels: relevance to secretion. Pflügers Arch 429: 231-239

VOGT K, MELLOR J, TONG G, NICOLL R (2000) The actions of synaptically released zinc at hippocampal mossy fiber synapses. Neuron 26: 187-196

WEISS JH, SENSI SL, KOH JY (2000) Zn2': A novel ionic mediator of neural injury in brain disease. TIPS 21: $395-401$

WENSINK J, LENGLET WJ, WIS RD, VAN DEN HAMER CJ (1987) The effect of dietary zinc deficiency on the mossy fiber zinc content of the rat hippocampus. A microbeam PIXE study. Particle Induced X-Ray Emission. Histochemistry 87: 65-69

WU LG, SAGGAU P (1997) Presynaptic inhibition of elicited neurotransmitter release. TINS 20: 204-212

XIE X, SMART TG (1994) Modulation of long-term potentiation in rat hippocampal pyramidal neurons by zinc. Pflugers Arch. 427: 481-486

ZAWAR C, PLANT TD, SCHIRRA C, KONNERTH A, NEMCKE B (1999) Cell-type specific expression of ATP-sensitive potassium channels in the rat hippocampus. J Physiol 514: 327-341 